\title{
CORROSÃO EM RESERVATÓRIO DE CONCRETO ARMADO EM FASE DE OBRA, ESTUDO DE CASO: POTENCIAL DE CORROSÃO, FRENTE DE CARBONATAÇÃO E PREVISÃO DE VIDA ÚTIL
}

\author{
G. Modesti ${ }^{1 *}$, C. C. Albert ${ }^{2}$, L. A. Modesti ${ }^{1}$ \\ *Autor de Contato: gmodesti@avalisinos.com.br \\ ${ }^{1}$ Avalisinos Engenharia e Consultoria, Novo Hamburgo, Brasil \\ ${ }^{2}$ Departamento de Engenharia Civil, Universidade do Vale do Rio do Sinos, São Leopoldo, Brasil
}

\begin{abstract}
RESUMO
Este estudo apresenta a análise e diagnóstico de um reservatório de água em concreto armado, com sinais de corrosão e eflorescências, num empreendimento em fase de obra. Foram realizadas inspeções do reservatório, ensaios de potencial de corrosão, frente de carbonatação, análise documental do concreto e foi estimada a evolução da frente da carbonatação ao longo do tempo. A estrutura foi dimensionada para classe de agressividade inferior ao recomendado e vícios construtivos resultaram em cobrimentos insuficientes, concreto mais permeável e avanço prematuro da carbonatação. Potenciais de corrosão mais negativos concentraram-se em zonas de reparos com argamassas com aditivos impermeabilizantes. De acordo com o modelo de previsão de vida útil, a estrutura não terá a durabilidade requerida.
\end{abstract}

Palavras chave: concreto armado; corrosão; potencial de corrosão; carbonatação; vida útil. 


\title{
CORROSION IN WATER TANK OF REINFORCED CONCRETE DURING CONSTRUCTION PHASE, CASE STUDY: CORROSION POTENTIAL, CARBONATION DEPTH AND PREDICTED SERVICE LIFE
}

\begin{abstract}
This study presents the analysis and diagnosis of a water tank of reinforced concrete with signs of corrosion and efflorescence, which is part of a building in the construction phase. The tank was inspected, corrosion potential and carbonation depth were measured, the documentary analysis of the concrete was carried out, and the evolution of the carbonation front over time was estimated. The structure was designed for an aggressiveness level lower than the recommended, and construction defects resulted in insufficient concrete cover, more permeable concrete, and premature advance of carbonation. More negative corrosion potentials were concentrated in repair areas with mortars with waterproofing additives. According to the predicted service life model, the structure will not have the required durability.

Keywords: reinforced concrete; corrosion; corrosion potential; carbonation; predicted service life.

\section{CORROSIÓN EN UN TANQUE DE AGUA DE HORMIGÓN ARMADO EN FASE DE CONSTRUCCIÓN, ESTUDIO DE CASO: POTENCIAL DE CORROSIÓN, FRENTE DE CARBONATACIÓN Y VIDA ÚTIL PREVISTA}

\begin{abstract}
RESUMEN
Este estudio presenta el análisis y diagnóstico de un tanque de agua de hormigón armado con signos de corrosión y eflorescencia, que forma parte de un edificio en fase de construcción. Se inspeccionó el tanque, se midió el potencial de corrosión y profundidad de carbonatación, se realizó el análisis documental del hormigón y se estimó la evolución del frente de carbonatación en el tiempo. La estructura fue diseñada para un nivel de agresividad menor al recomendado, y los defectos de construcción dieron como resultado una cobertura de concreto insuficiente, concreto más permeable y avance prematuro de carbonatación. Los potenciales de corrosión más negativos se concentraron en las áreas de reparación con morteros con aditivos impermeabilizantes. Según el modelo de vida útil previsto, la estructura no tendrá la durabilidad requerida.
\end{abstract}

Palabras clave: hormigón armado, corrosión; potencial de corrosión; carbonatación; vida útil.

\section{INTRODUÇÃO}

A corrosão do aço no concreto armado é a principal responsável pela deterioração precoce das estruturas, conforme Angst (2018). A consequência direta da corrosão é a redução da seção da armadura, podendo resultar em diminuição da resistência mecânica dos elementos e riscos estruturais em casos avançados (Hansson, 2016). Complementarmente, as tensões internas geradas pelos produtos de corrosão provocam a fissuração e o destacamento do concreto de cobrimento, bem como a perda de aderência entre o aço e o concreto. Manchas de produtos de corrosão também podem ser identificadas na superfície da estrutura (Gentil, 2014; Mehta e Monteiro, 2014).

Em condições normais, o ambiente alcalino do concreto proporciona a formação de um filme de passivação no aço, o qual controla a movimentação iônica na interface aço/concreto e protege o metal das reações eletroquímicas de corrosão. Ocorre que agentes agressivos podem desestabilizar e romper este filme protetor, com destaque para o efeito de $\mathrm{CO}_{2}$ e íons cloreto (Hansson, 2016; 
Andrade e Bujak, 2013; Chemrouk, 2015). No caso da carbonatação, o $\mathrm{CO}_{2}$ atmosférico penetra pela rede de poros do concreto e consome a reserva alcalina de $\mathrm{Ca}(\mathrm{OH})_{2}$ da solução de poros, resultando na queda do pH e despassivação da armadura. Já os íons cloreto atacam o filme de passivação pontualmente e catalisam as reações eletroquímicas, gerando corrosão acelerada em pites (Gentil, 2014). A umidade do concreto pode intensificar tais processos, sendo que concretos carbonatados costumam apresentar taxas de corrosão até 100 vezes maiores quando sujeitos a umidade elevada, de acordo com Stefanoni et. al. (2018, 2019). Ainda, ciclos de molhagem e secagem são especialmente críticos para a corrosão.

Para o dimensionamento das estruturas, é essencial determinar o nivel de agressividade ambiental a que o elemento estará exposto, conforme disposto na NBR 6118 (ABNT, 2014), visto que o ambiente influencia significativamente a corrosão (Lima, 2011). Para reservatórios em concreto armado, a variação do nível de água e a presença de cloretos na água potável caracterizam condição crítica, requerendo atenção especial dos projetistas. No entanto, esta atenção costuma ser neglicenciada, sendo comum o dimensionamento de reservatórios a exemplo do restante da estrutura, apesar do cenário mais agressivo a que o concreto está exposto neste ambiente.

Vícios construtivos podem intensificar os mecanismos de corrosão e antecipar a sua iniciação e, portanto, o final da vida útil da estrutura, conforme Chemrouk (2015). É o caso do mal uso ou ausência de espaçadores durante a execução, implicando em camadas de concreto de cobrimento insuficientes para a armadura (Angst et. al., 2020). Concretos muito permeáveis com relações a/c e fcks abaixo do recomendado facilitam o ingresso dos agentes agressivos (Chemrouk, 2015). Além disso, reparos no cobrimento da armadura devem ser realizados com materiais de desempenho similar ao concreto do todo, a fim de não gerar gradientes de potencial e induzir o estabelecimento de células eletroquímicas (Gentil, 2014). Uma vez que a corrosão tenha iniciado, destaca-se a importância da realização de diagnóstico especializado para determinar o seu grau de severidade e previsão da vida útil residual da estrutura. Assim, há amparo técnico para a tomada de decisões a respeito dos procedimentos de reparo ou eventual demolição necessários.

Desta forma, o objetivo do estudo é apresentar a inspeção e análise realizada em um reservatório de água superior, em concreto armado, com sinais de corrosão e eflorescências. O elemento é parte de um prédio residencial de padrão construtivo alto, com vinte pavimentos, localizado na região Sul do Brasil. O reservatório possui estrutura, paredes e cobertura em concreto armado, tendo sido concretado há aproximadamente 2 anos, porém ainda fora de uso, pois o empreendimento está em fase de obra. Neste período, o reservatório esteve preenchido com água por apenas cerca de 3 meses, quando surgiram as manifestações patológicas. No restante do tempo, esteve vazio. $\mathrm{O}$ procedimento experimental consistiu na inspeção do reservatório, seguido pela realização de ensaios não destrutivos, com verificação da profundidade de carbonatação e potencial de corrosão da estrutura. A partir destes resultados e da análise documental do concreto, foi estimada a evolução da frente da carbonatação ao longo do tempo, pelo modelo de Possan (2010), a fim de determinar a vida útil da estrutura do reservatório em diferentes cenários. Reforça-se a importância da análise da corrosão em estruturas reais, a fim de integrar o conhecimento científico à aplicação prática na construção civil, processo ainda em avanço lento na realidade brasileira.

\section{METODOLOGIA}

Verificou-se, por meio de análise visual, a existência de manifestações patológicas, realizando-se o mapeamento destas. Estas foram analisadas frente à idade da estrutura e métodos construtivos, baseando-se em anamnese prévia. A inspeção foi restrita ao compartimento do reservatório acima da "Laje 4", indicado na Figura 1, tendo em vista que as manifestações patológicas se repetem da mesma forma em todos os outros compartimentos, porém em menor grau. 
Conforme informações do projeto estrutural, foi previsto concreto com $\mathrm{fc}_{\mathrm{k}}=30 \mathrm{MPa}$, cobrimentos para laje em $20 \mathrm{~mm}$ e cobrimentos para vigas e pilares em $25 \mathrm{~mm}$. O concreto foi definido com relação a/c de 0,55 e consumo mínimo de cimento de $320 \mathrm{~kg} / \mathrm{m}^{3}$. Sendo assim, deduz-se que foi considerada a classe de agressividade ambiental (CAA) III (agressividade forte) na relação a/c, consumo de cimento e $\mathrm{fc}_{\mathrm{k}}$. Já para os cobrimentos, o projeto considerou a classe de agressividade ambiental (CAA) II, com redução de $5 \mathrm{~mm}$ no cobrimento, em função de ter sido adotado concreto com classe de resistência acima do mínimo para a classe desta zona de agressividade, em consonância com a NBR 6118 (ABNT, 2014). Importante destacar que os cobrimentos nominais especificados na normativa consideram uma tolerância $(\Delta c)$ de $10 \mathrm{~mm}$ (erro de execução aceitável). Desta forma, é admissível, após a finalização da execução, $10 \mathrm{~mm}$ a menos do que o especificado para garantir o atendimento ao seu critério. Ou seja, em vigas e pilares da CAA II, onde está especificado cobrimento nominal de $30 \mathrm{~mm}$, se admite, após a execução, cobrimento mínimo de $20 \mathrm{~mm}$.

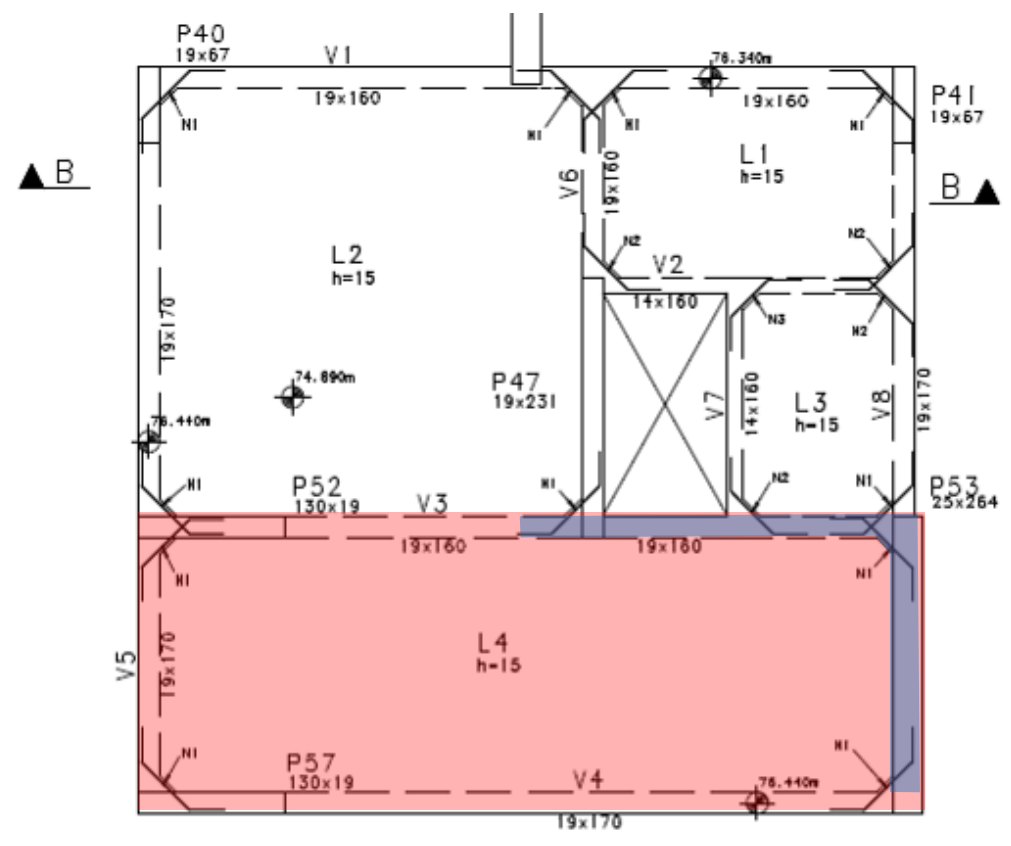

Figura 1. Indicação (em vermelho) do compartimento inspecionado, com destaque (em cinza) para zona de medição dos potenciais de corrosão.

Em relação ao concreto utilizado, foi informado pela incorporadora, que na dosagem fora adicionado aditivo impermeabilizante por cristalização. Entretanto, não consta na "carta traço" apresentada pelo fornecedor de concreto informações relativas ao produto. Complementarmente, os furos dos travamentos das formas foram tamponados com argamassa com aditivo impermeabilizante que, conforme informações do fabricante, costuma atingir $40 \mathrm{MPa}$ aos 28 dias. Foi informado que o controle tecnológico do concreto indicou que foi atendido o $\mathrm{fc}_{\mathrm{k}}$ especificado para o concreto do reservatório.

\subsection{Ensaios não destrutivos}

Realizou-se o ensaio de pacometria para identificação da posição das armaduras a fim de balizar o ensaio de potencial de corrosão. O ensaio de potencial seguiu as recomendações da RILEM TC154EMC (RILEM, 2003) e da ASTM C876 (ASTM, 2015). Tal análise foi restrita a 25\% da área de paredes na V03 (metade da área de parede) e P53 (totalidade), tendo em vista a repetição das manifestações patológicas ao longo da estrutura. A Figura 1 indica a zona de ensaios, em azul. 
No procedimento do potencial de corrosão, foi realizada pré-molhagem de toda a superfície de medição, conforme o "Método A" da ASTM C876 (ASTM, 2015). O eletrodo de referência utilizado foi de Cobre/Sulfato de Cobre $\left(\mathrm{Cu} / \mathrm{CuSO}_{4}\right)$. Foi utilizado grid de aproximadamente $0,30 \mathrm{~m}$ entre pontos de medição na parte central dos vergalhões horizontais e verticais, com verificações pontuais em locais com presença de óxido de ferro. Ressalta-se que o ensaio foi realizado com temperatura aproximada de $15^{\circ} \mathrm{C}$, sem precipitação nos cinco dias anteriores ao ensaio. A Figura 2 ilustra a medição do potencial de corrosão, com conexão do voltímetro à armadura e movimentação do eletrodo de referência ao longo da estrutura.

A análise de resultados se deu por meio de mapas de contorno equipotenciais, conforme item 9 da ASTM C876 (ASTM, 2015) e item 6.6.1 da RILEM TC154-EMC (RILEM, 2003), visando identificar pontos de maior probabilidade de despassivação de armaduras e corrosão. Baseado nestes levantamentos, determinaram-se os locais para verificação das condições reais das armaduras por meio de janela de inspeção, bem como da posição da frente de carbonatação e do cobrimento efetivo. Ao total, foram abertas 12 janelas de inspeção. A frente de carbonatação foi determinada por meio da aspersão de timolftaleína (1\% em solução) que assume cor azul em pH acima de 10,5 e torna-se incolor em pH inferior à 10,5, conforme a Figura 2.
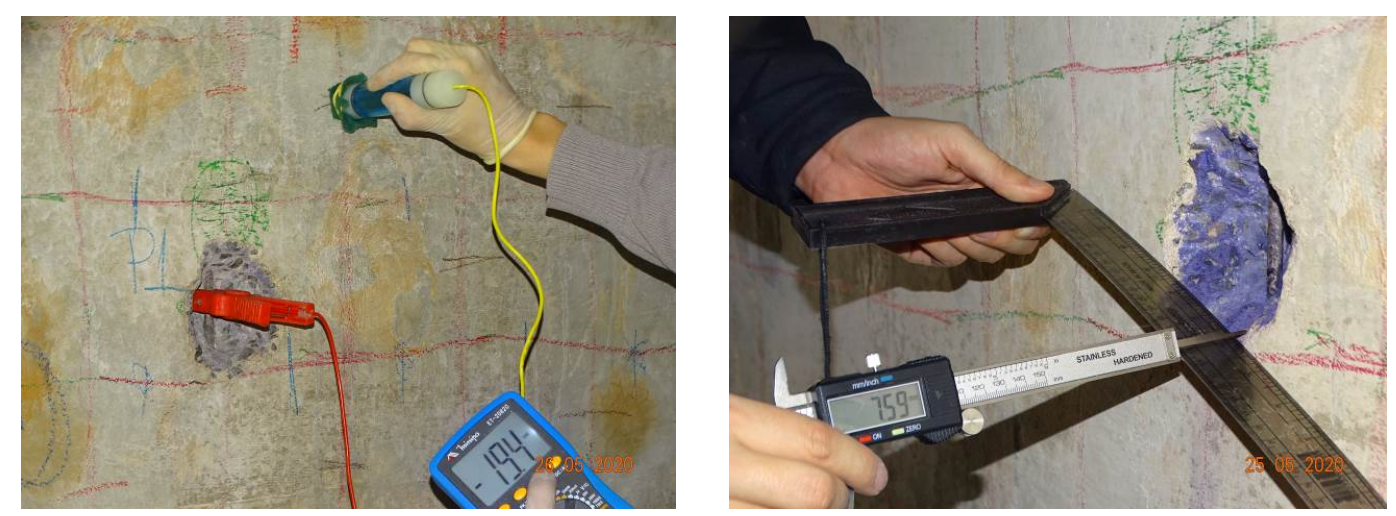

Figura 2. Exemplo da verificação do potencial de corrosão, frente de carbonatação e cobrimentos.

\subsection{Previsão da vida útil}

As informações coletadas, somadas ao controle tecnológico do concreto, especificações de projeto e das normas pertinentes, foram utilizadas em modelo de previsão de vida útil, buscando verificar a probabilidade de atendimento aos critérios de vida útil previstos na NBR 15575-2 (ABNT, 2013). Utilizou-se o modelo de Possan (2010), exposto em (1), para previsão de carbonatação, tendo em vista ter sido elaborado considerando o estado da arte nacional bem como as características dos produtos nacionais (ex: cimento). O modelo de carbonatação foi utilizado pois, até o momento da inspeção, o reservatório esteve durante a maior parte do tempo vazio, com influência mínima de cloretos e mais relacionada à carbonatação. As variáveis consideradas são expostas na Tabela 1.

$$
y=k_{c}\left(\frac{20}{f_{c}}\right)^{k_{f c}} \cdot\left(\frac{t}{20}\right)^{\frac{1}{2}} \cdot \exp \left[\left(\frac{k_{a d} \cdot a d^{\frac{3}{2}}}{40+f_{c}}\right)+\left(\frac{k_{c o_{2}} \cdot C O_{2}^{\frac{1}{2}}}{60+f_{c}}\right)-\left(\frac{k_{U R} \cdot(U R-0,58)^{2}}{100+f_{c}}\right)\right] \cdot k_{c e}
$$

Tabela 1. Variáveis adotadas no modelo de previsão de vida útil de Possan (2010).

\begin{tabular}{|c|c|c|}
\hline \multirow{2}{*}{ Variável } & Cimento & \multirow{2}{*}{ Descrição da variável } \\
\cline { 2 - 2 } & CP II F &
\end{tabular}




\begin{tabular}{|c|c|c|}
\hline $\mathbf{y}$ & & profundidade de carbonatação média do concreto em mm \\
\hline fc & $30 \mathrm{MPa}$ & $\begin{array}{l}\text { resistência característica à compressão axial do concreto, em MPa. Variado em } \\
+/-5 \mathrm{MPa} \text { para determinação dos cenários otimista e pessimista. Mesmo } \\
\text { procedimento realizado considerando f } \mathrm{f}_{\mathrm{k}} \text { da CAA III e ABNT NBR } 12655\end{array}$ \\
\hline $\mathrm{kc}$ & 21,68 & fator variável referente ao tipo de cimento empregado (CP II F) \\
\hline $\mathrm{kfc}$ & 1,5 & $\begin{array}{l}\text { fator variável referente à resistência à compressão axial do concreto, em } \\
\text { função do tipo de cimento utilizado (CP II F) }\end{array}$ \\
\hline $\mathrm{t}$ & variável & $\begin{array}{l}\text { idade do concreto, em anos, variando de } 0 \text { a } 53 \text { anos ( } 50 \text { anos de VUP }+3 \text { anos } \\
\text { de execução) }\end{array}$ \\
\hline $\mathrm{ad}$ & 0 & teor de adição pozolânica no concreto, em \% em relação à massa de cimento \\
\hline $\mathrm{kad}$ & 0,24 & $\begin{array}{l}\text { fator variável referente às adições pozolânicas do concreto, em função do tipo } \\
\text { de cimento utilizado }\end{array}$ \\
\hline UR & 0,76 & umidade relativa média, em $\% * 0,01$, vide dados históricos. \\
\hline kur & 1100 & $\begin{array}{l}\text { fator variável referente à umidade relativa, em função do tipo de cimento } \\
\text { utilizado (CP II F) }\end{array}$ \\
\hline $\mathrm{CO} 2$ & 0,0415 & teor de $\mathrm{CO} 2$ da atmosfera, em $\%$, equivalente a $415 \mathrm{ppm}$. \\
\hline $\mathrm{kco} 2$ & 18 & $\begin{array}{l}\text { fator variável referente ao teor de } \mathrm{CO} 2 \text { do ambiente, em função do tipo de } \\
\text { cimento utilizado (CP II F) }\end{array}$ \\
\hline kce & & $\begin{array}{l}\text { fator variável referente à exposição à chuva, em função das condições de } \\
\text { exposição da estrutura }\end{array}$ \\
\hline \multicolumn{3}{|c|}{$\begin{array}{l}\text { Observação: O fator kce foi considerado como } 1,30 \text {, equivalente à ambiente interno protegido da chuva } \\
\text { e sem água até os } 3 \text { anos (obras). Durante o uso foi reduzido para } 0,65 \text { por estar submerso. Variado em } \\
+/-10 \% \text { para determinação dos cenários otimista e pessimista. }\end{array}$} \\
\hline
\end{tabular}

\section{RESULTADOS}

Foram identificadas as seguintes manifestações patológicas na superfície do reservatório, indicando em croqui sua posição na Figura 3. As Figuras 4 e 5 exemplificam os danos.

- Armaduras aparentes na laje de cobertura e nas mísulas, devido ao cobrimento insuficiente dos vergalhões;

- Corrosão das armaduras aparentes;

- Manchas de produtos de corrosão pontuais com lixiviação de produtos pulverulentos e de cor marrom;

- Eflorescências na laje de cobertura, devido à lixiviação de sais solúveis presentes no concreto. 


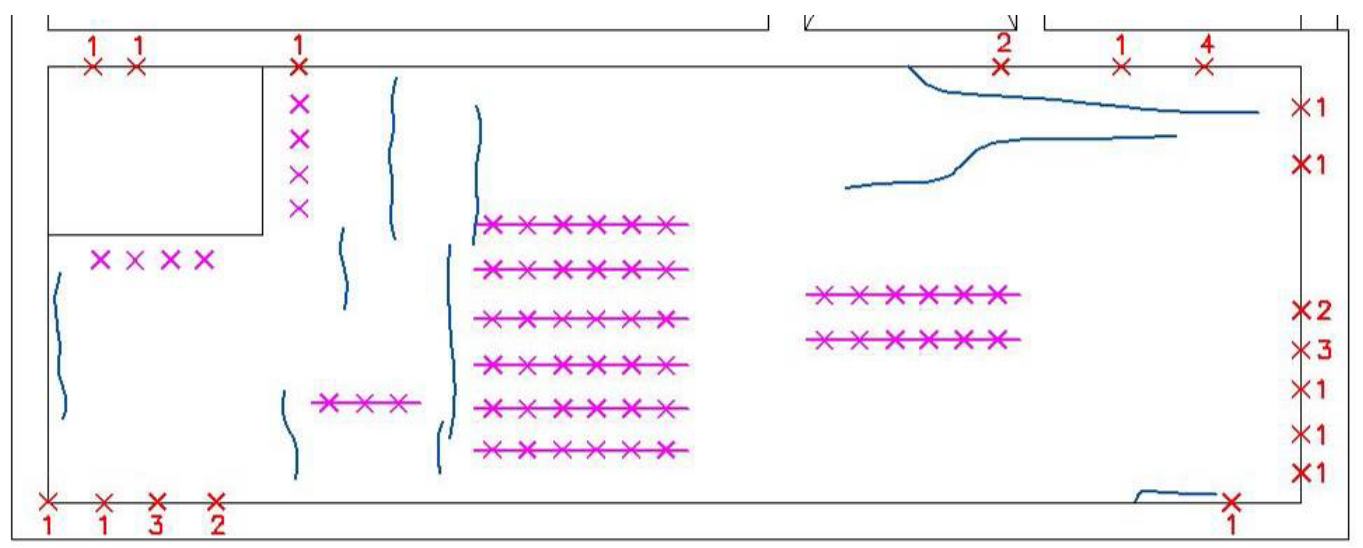

\section{Legenda \\ $\times$ Pontos com bolhas de corrosão na viga-parede \\ $\times$ Pontos com bolhas de corrosão na laje de teto \\ $-*$ Armaduras aparentes \\ Eflorescência}

Figura 3. Mapeamento das manifestações patológicas no reservatório analisado.
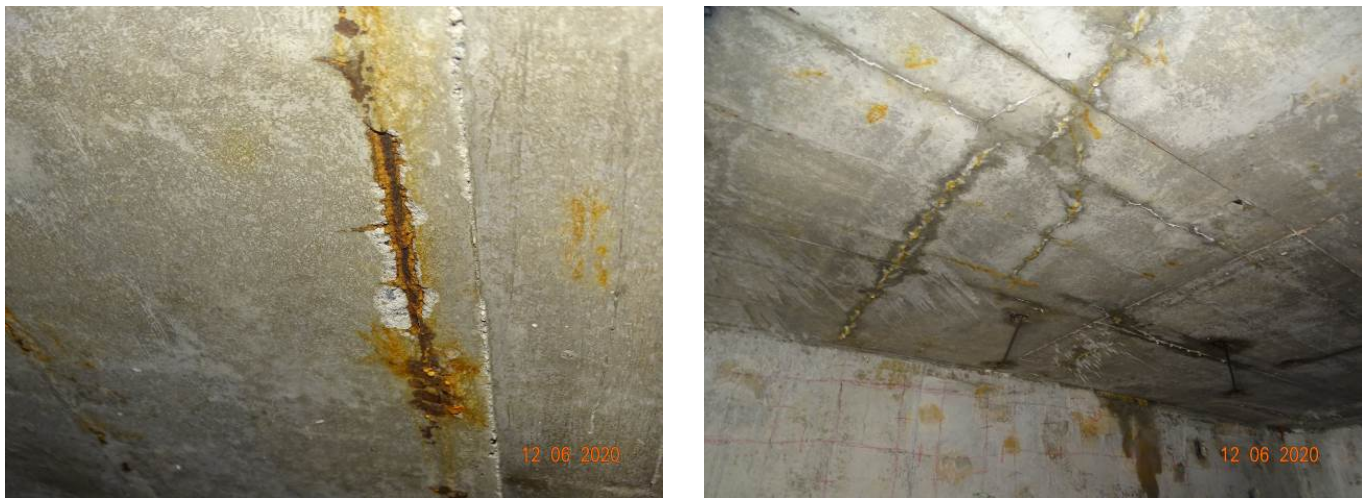

Figura 4. Armaduras em processo de corrosão e eflorescências molhadas, pela infiltração de água que ocorre na laje superior (face superior ainda sem impermeabilização).
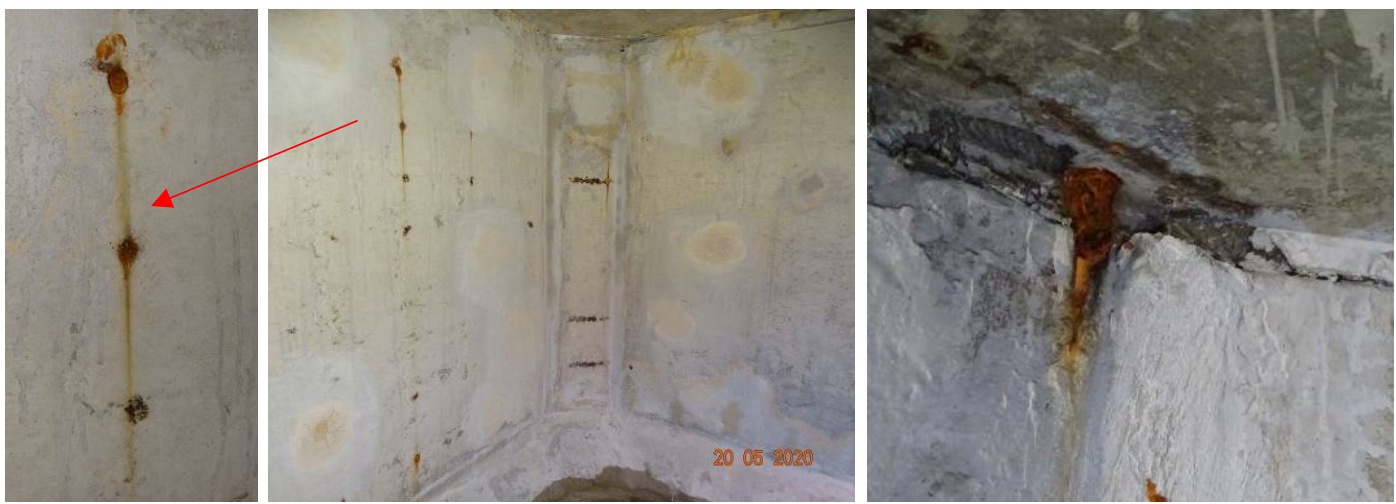

Figura 5. Exemplo de armadura aparente na mísula e de pontos de corrosão (bolhas) de arames nas vigas parede.

As armaduras aparentes e corrosão provocadas pela deficiência de cobrimento estão diretamente relacionadas à execução, sendo provocadas pela utilização inadequada dos espaçadores, seja pelo elevado espaçamento entre si ou por movimentações durante a concretagem (pressão e vibração). 
As eflorescências estão relacionadas à precipitação de sais solúveis que são carreados à superfície pela presença de umidade (Menezes et. al., 2006). Junginger e Medeiros (2002) complementam que a manifestação patológica tende a ocorrer quando há coexistência de: água, sais solúveis em água e condições ambientais e de estrutura que proporcionem a percolação e evaporação da água (fluxo de água). É o caso de concretos porosos, devido à relação a/c elevada, e em ambientes com umidade, como o verificado no reservatório. Por fim, ressalta-se que não foram identificadas fissuras com abertura superior ao limite estabelecido na NBR 6118 (ABNT, 2014).

\subsection{Mapas de potencial de corrosão}

O ensaio de potencial de corrosão foi realizado nas partes previamente indicadas do reservatório, englobando a viga V3 e parte da P53. Apresenta-se nas Figuras 6 e 7 os mapas de contorno equipotenciais para os elementos analisados, indicando, em caixas cinza, as janelas para conexão do equipamento e, em círculos roxos, os locais de janela de inspeção abertas posteriormente. Todos os potenciais são em relação ao eletrodo padrão $\mathrm{Cu} / \mathrm{CuSO}_{4}$.

A partir da análise da distribuição dos potenciais da Figura 8 , verifica-se que $83 \%$ dos potenciais identificados estão entre $-10 \mathrm{mV}$ e $-70 \mathrm{mV}, 8 \%$ estão entre $-70 \mathrm{mV}$ e $-100 \mathrm{mV}$ e $11 \%$ entre $-100 \mathrm{mV}$ e $-142 \mathrm{mV}$. Os picos mais eletronegativos estão em locais adjacentes às vedações com argamassa com aditivo impermeabilizante, onde se atinge potenciais de até $-142 \mathrm{mV}$, destoando do restante. Os gradientes de potencial são pequenos e, de forma geral, indicam a passivação das armaduras.

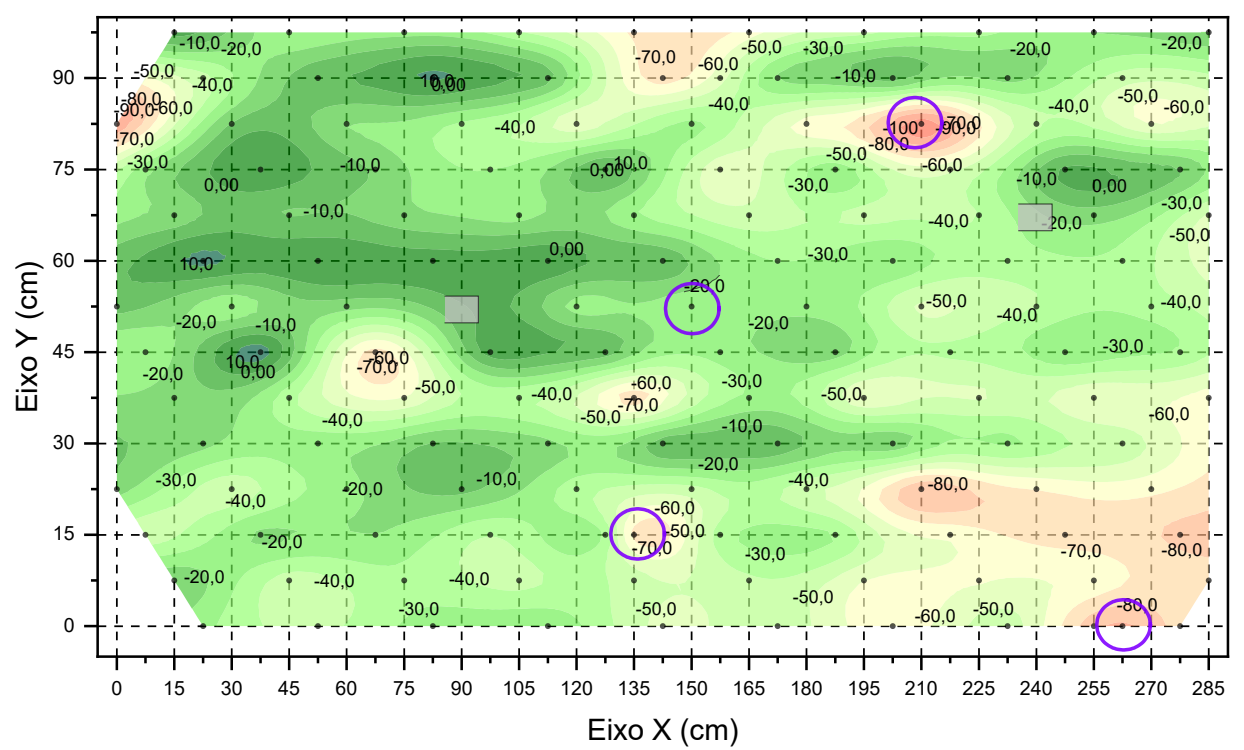

Figura 6. Mapa de linhas de contorno equipotenciais para a V3 (parede longitudinal). 


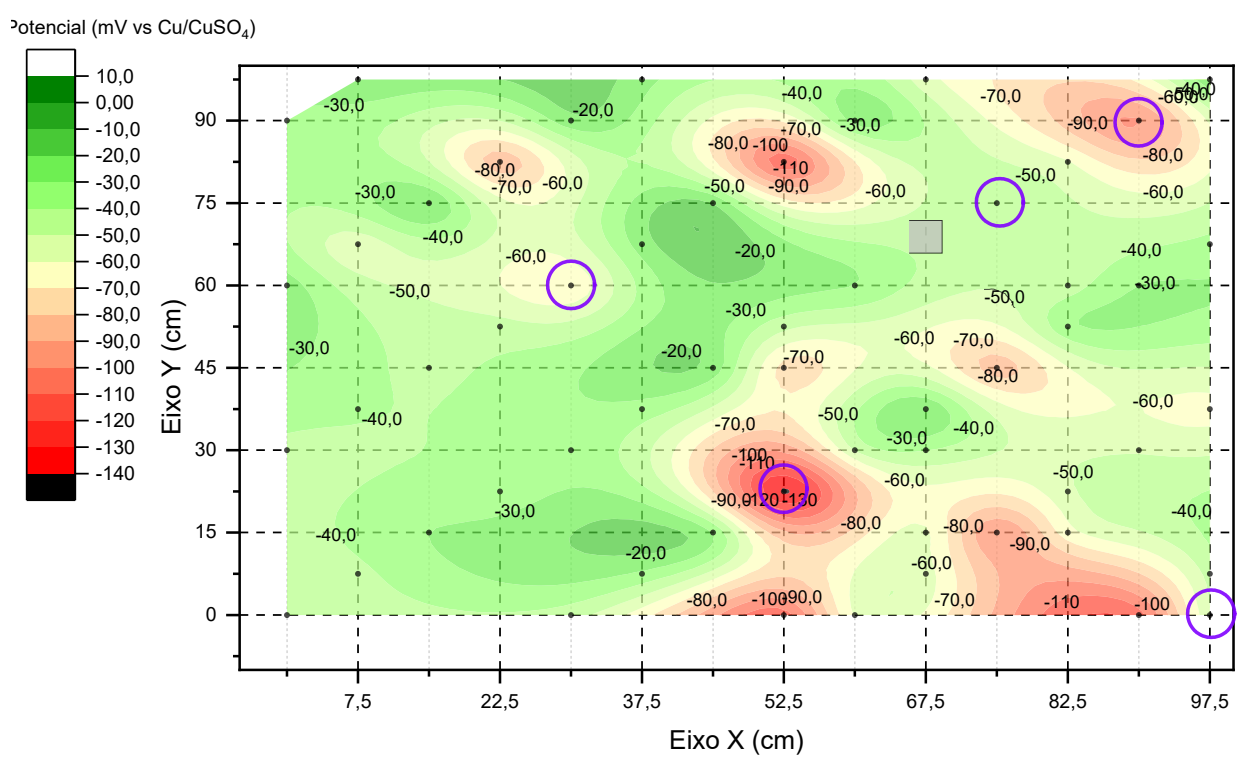

Figura 7. Mapa de linhas de contorno equipotenciais para o P53 (parede transversal).
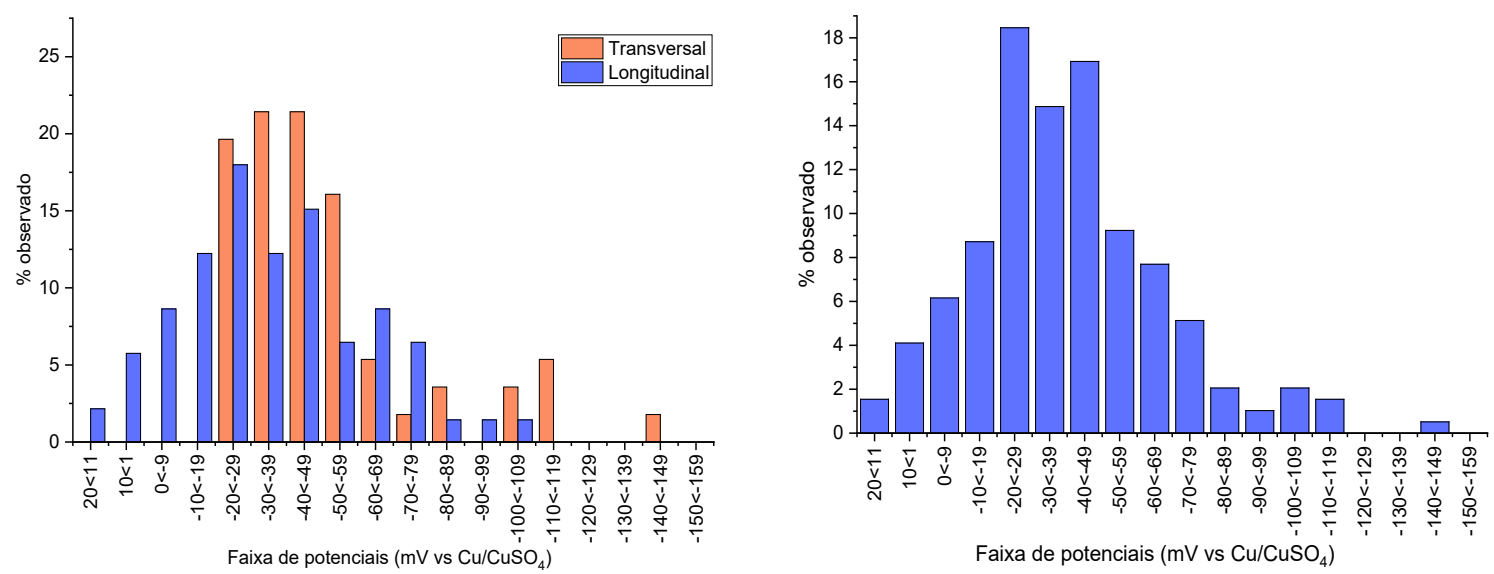

Figura 8. Distribuição dos potenciais para (a) cada parede e (b) considerando o conjunto.

\subsection{Janelas de inspeção, frente de carbonatação e estado das armaduras}

A partir do mapeamento, selecionaram-se 9 locais adicionais (somados às 3 janelas originais para conexão do equipamento) para abertura de janelas de inspeção, exibidos na Figura 9. Foram selecionados pontos em 3 situações distintas:

- Potenciais dentro da faixa média para constatação da situação geral das armaduras;

- Potenciais em valores mais eletronegativos, para identificação da pior situação das armaduras;

- Potenciais em regiões de gradientes elevados, para identificação de eventuais despassivações localizadas. 


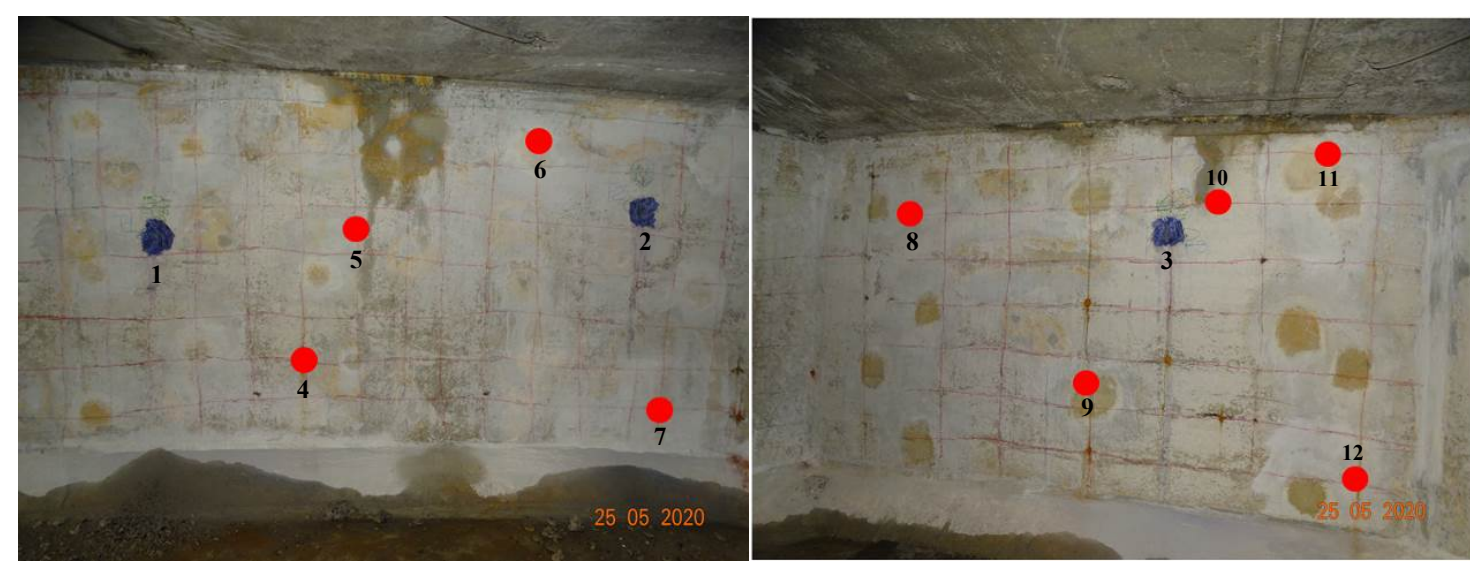

Figura 9. Indicação das janelas de inspeção.

Apresenta-se na Tabela 2 a frente de carbonatação e cobrimentos das janelas de inspeção. Verificou-se uma frente de carbonatação média de 4,6 mm após 2 anos, com média mínima em uma janela específica de 2,1 mm (janela 9) e máxima de 6,7 $\mathrm{mm}$ (janela 3). Em relação aos cobrimentos, em sua maioria estão entre $11,5 \mathrm{~mm}$ e $18,8 \mathrm{~mm}$, com duas janelas iguais ou inferiores a 4,0 $\mathrm{mm}$ e uma atingindo $30,3 \mathrm{~mm}$. 
Tabela 2. Frentes de carbonatação e cobrimentos das janelas de inspeção.

\begin{tabular}{|c|c|c|c|c|c|c|c|c|c|c|}
\hline \multirow[t]{2}{*}{ Janela } & \multirow{2}{*}{$\begin{array}{l}\text { Ecorr } \\
(\mathrm{mV})\end{array}$} & \multicolumn{4}{|c|}{$\begin{array}{c}\text { Frente de } \\
\text { carbonatação (mm) }\end{array}$} & \multirow{2}{*}{\multicolumn{2}{|c|}{$\begin{array}{l}\text { Cobrimento } \\
\quad(\mathrm{mm})\end{array}$}} & \multirow{2}{*}{$\begin{array}{c}\text { CAA II } \\
\text { NBR } 6118\end{array}$} & \multirow[t]{2}{*}{ Corrosão } & \multirow[t]{2}{*}{ Observação } \\
\hline & & 1 & 2 & 3 & Média & & & & & \\
\hline 1 & - & 4,6 & 4,6 & 7,6 & 5,6 & 30,3 & 30,3 & $\operatorname{Sim}$ & Não & Passivado \\
\hline 2 & - & 4,3 & 3,7 & 5,3 & 4,4 & 14,5 & 14,5 & Não & Não & Passivado \\
\hline 3 & - & 8,2 & 5,0 & 7,0 & 6,7 & 18,8 & 18,8 & Sim & Não & Passivado \\
\hline 4 & -75 & 3,4 & 5,6 & 2,8 & 4,0 & 11,5 & 11,5 & Não & Não & $\begin{array}{l}\text { Passivado, corrosão no } \\
\text { arame }\end{array}$ \\
\hline 5 & -27 & 6,8 & 5,5 & 3,5 & 5,3 & 17,1 & 17,1 & Sim & Não & Passivado \\
\hline 6 & -108 & 8,3 & 4,4 & 0,0 & 4,2 & 18,2 & 18,2 & Sim & Não & Passivado (Adit. Imp.) \\
\hline 7 & -87 & 5,1 & 2,4 & 2,9 & 3,5 & 3,6 & 3,6 & Não & Sim & $\begin{array}{l}\text { Corrosão ponta sem } \\
\text { cobrimento }\end{array}$ \\
\hline 8 & -67 & 4,3 & 4,0 & 3,3 & 3,9 & 13,7 & 13,7 & Não & Não & Passivado \\
\hline 9 & -142 & 0,8 & 5,6 & 0,0 & 2,1 & 15,6 & 11,6 & Não & Não & Passivado (Adit. Imp.) \\
\hline 10 & -45 & 5,3 & 8,3 & 6,2 & 6,6 & 13,1 & 13,1 & Não & Não & Passivado \\
\hline 11 & -101 & 3,6 & 2,9 & 3,1 & 3,2 & 21,5 & 21,5 & Sim & Não & Passivado (Adit. Imp.) \\
\hline 12 & -51 & 5,7 & 3,8 & 6,4 & 5,3 & 4,0 & 4,0 & Não & Sim & Corrosão arame e gancho \\
\hline
\end{tabular}

Nota-se que, das 12 janelas, apenas em cinco situações o cobrimento atende ao mínimo previsto para a CAA II de $15 \mathrm{~mm}$ para vigas e pilares $(25 \mathrm{~mm}-10 \mathrm{~mm})$. Nos demais casos, o cobrimento restou inferior ao necessário. Nenhuma armadura atenderia a CAA IV. Nas janelas 7 e 12, exibidas na Figura 10, constatou-se princípio de corrosão do aço. Isso ocorre devido ao baixo cobrimento já atingido pela frente de carbonatação, resultando na despassivação daquelas armaduras. Especificamente em relação à janela 12, o cobrimento de $4 \mathrm{~mm}$ se refere a um gancho que se desprendeu da malha durante a concretagem, sendo que o cobrimento das armaduras principais foi de $13 \mathrm{~mm}$, ainda aquém do necessário para atendimento à NBR 6118 (ABNT, 2014), porém suficiente para mantê-la passivada nas condições atuais.
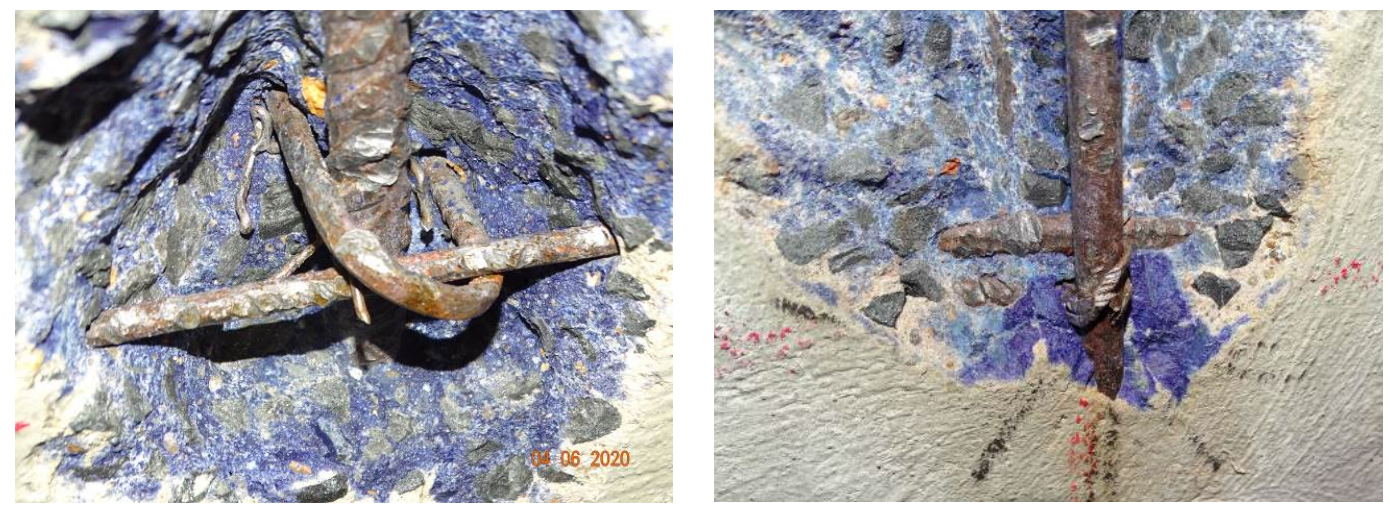

Figura 10. Detalhe do gancho da J12 e do vergalhão com cobrimento mínimo na J7, ambos com princípio de corrosão.

Comparando a situação real com os potenciais verificados, nota-se que aqueles inferiores a -100 mV se referem a locais próximos de reparos com a argamassa com aditivo impermeabilizante. Nestas regiões, pelas diferenças de aeração, umidade e porosidade do meio, estabelece-se uma diferença de potencial nas armaduras, sem relação com probabilidade de corrosão (pois permanece passivada). A diferença entre a maior distribuição de potenciais $(-40 \mathrm{mV})$ indicativos de passivação e daqueles com indícios de início de corrosão foi de aproximadamente $40 \mathrm{mV}$. 
Quanto à passivação das armaduras, as janelas de inspeção comprovam a situação estimada pelo ensaio de potencial de corrosão, de passivação majoritária das armaduras, tendo em vista que a frente de carbonatação, na situação atual, é inferior ao cobrimento de concreto. As exceções ocorrem nos locais com cobrimentos inferiores a $5 \mathrm{~mm}$ nas lajes e paredes.

Adicionalmente, foram abertas janelas de inspeção superficiais nos locais com pontos de corrosão. Identificou-se que a corrosão era proveniente dos arames que restaram superficiais, dentro da faixa já despassivada, porém a armadura principal estava passivada. A corrosão acelerada destes locais (manchas) ocorreu quando houve o enchimento do reservatório, que aumentou a umidade superficial porque o concreto estava poroso (o que acelerou a carbonatação) e a armadura era superficial, situações que aceleraram o processo corrosivo.

\subsection{Análise das características do concreto}

Em relação a NBR 6118 (ABNT, 2014), constatou-se pela documentação que o concreto fornecido possui relação a/c de 0,67 (205 1 de água para $308 \mathrm{~kg}$ de cimento), superior ao limite máximo de 0,60 especificado para a CAA II, acima de 0,50 pela NBR 12655 (ABNT, 2015) e acima de 0,55 especificado pelo projetista. Isto provocou concreto com maior porosidade e permeabilidade a agentes agressivos, até o momento $\mathrm{CO}_{2} \mathrm{e}$, durante o uso, cloretos presentes na água do reservatório. Nas condições atuais, com o reservatório vazio, considerando a umidade relativa média anual da região de $76 \%$, tem-se maior velocidade de carbonatação, porém baixa velocidade de corrosão quando despassivado. Uma vez cheio de água, a velocidade de carbonatação tende a diminuir, pois o concreto estará saturado. Entretanto, as zonas de molhagem e secagem, como a face inferior da tampa superior e zonas próximas ao topo, tendem a ter umidade em faixa de corrosão acelerada.

A resistência à corrosão das armaduras por cloretos é determinada pela relação entre hidroxilas $(\mathrm{pH})$ e os íons cloretos livres $\left(\mathrm{Cl}^{-}\right)$, conhecida como relação $\left[\mathrm{Cl}^{-}\right] /\left[\mathrm{OH}^{-}\right]$(Andrade e Bujak, 2013). À medida que ocorrer o ingresso de cloretos (fase de uso), as zonas carbonatadas, onde o $\mathrm{pH}$ do concreto é menor, apresentarão menor resistência a estes agentes agressivos. Isso ocorre porque a sua resistência está diretamente relacionada com a quantidade de hidroxilas na solução dos poros do concreto (maior teor crítico de cloretos em pH elevado (Modesti, 2020; Revert et. al., 2018). Como consequência, tem-se a maior probabilidade de corrosão por cloretos nos locais com $\mathrm{pH}$ reduzido, com período de iniciação mais curto pelo efeito combinado de cloretos e carbonatação (Figueira et. al., 2018; Zhu et. al., 2016).

Reforça-se que foram consideradas em projeto as características para classe de agressividade ambiental II e III. Porém, no caso de reservatórios de água cuja superfície esteja diretamente exposta à água tratada (que possui cloretos), como a projetada, conforme a NBR 6118 (ABNT, 2014), o reservatório deveria ter cobrimento enquadrado como CAA IV (cobrimento de 50mm para vigas e $45 \mathrm{~mm}$ para lajes), vide alínea $C$ da Tabela 7.2 da norma. Complementarmente, a NBR 12655 (ABNT, 2015) especifica que em reservatórios, considera-se fck $\geq 35 \mathrm{MPa}$ e relação $\mathrm{a} / \mathrm{c} \leq 0,50$. Portanto, verifica-se que o projeto não atendeu a estes requisitos.

\subsection{Modelos de previsão de vida útil}

Considerando a frente de carbonatação real e as características do concreto empregado, utilizou-se o modelo de Possan (2010) para previsão da evolução da frente de carbonatação ao longo da fase de uso. O modelo foi ajustado para considerar que a presença de água. Embora a velocidade de corrosão por carbonatação seja mínima no trecho da estrutura saturado, no trecho próximo ao topo e na tampa superior, há molhagem e secagem, acelerando este processo. Além disso, a redução de pH também provoca a diminuição da resistência à cloretos, sendo importante a sua determinação. Não foram utilizados modelos de evolução de cloretos, devido às incertezas existentes na sua utilização em estruturas novas, ainda sem presença efetiva do agente agressivo. Entretanto, considerando a alta permeabilidade do concreto, provocado pela elevada relação a/c, entende-se 
muito provável que o agente agressivo atinja a armadura, assim como no caso da carbonatação. Foram feitas três simulações partindo da situação que atende a CAA (classe de Agressividade Ambiental) IV, depois CAA II, por fim a situação atual.

\subsubsection{Projeção com concreto atendendo a NBR 12655 e cobrimentos atendendo a CAA IV da NBR 6118}

A Figura 11 exibe a evolução da frente de carbonatação ao longo do tempo para as condições ideais de atendimento à NBR 12655 (ABNT, 2015) para as características do concreto e cobrimentos relativos à CAA IV da NBR 6118 (ABNT, 2014). Neste caso, com adequação aos itens mais conservadores das normativas, a frente de carbonatação não atingiria as lajes nem as vigas parede durante toda a vida útil da estrutura, com margem de segurança superior à $25 \mathrm{~mm}$ (pois a carbonatação se torna irrelevante frente aos cloretos). Portanto, esta é a situação ideal que garantia segurança estrutural ao reservatório por todo o período.

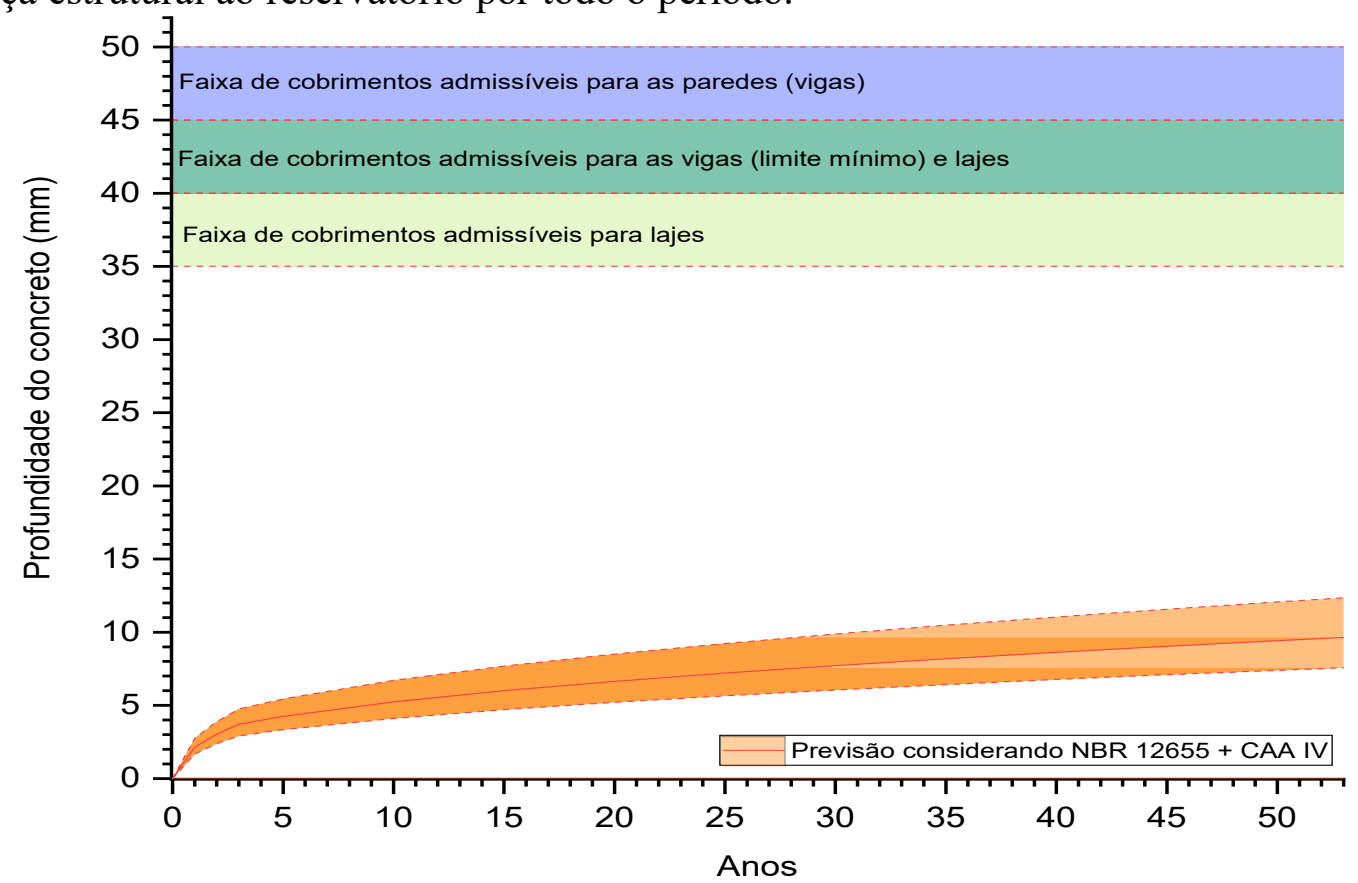

Figura 11. Evolução da frente de carbonatação para concreto atendendo a NBR 12655 e cobrimentos atendendo a CAA IV da NBR 6118.

3.5.2 Projeção com mesmo concreto do projeto e cobrimentos atendendo a CAA II da NBR 6118 Nesta segunda situação, adotou-se o concreto mais poroso e com menor $\mathrm{fc}_{\mathrm{k}}$ utilizado na situação real, mas considerando-se os cobrimentos determinados na NBR 6118 (ABNT, 2014) para a CAA II, especificados em projeto. Os resultados são apresentados na Figura 12. 


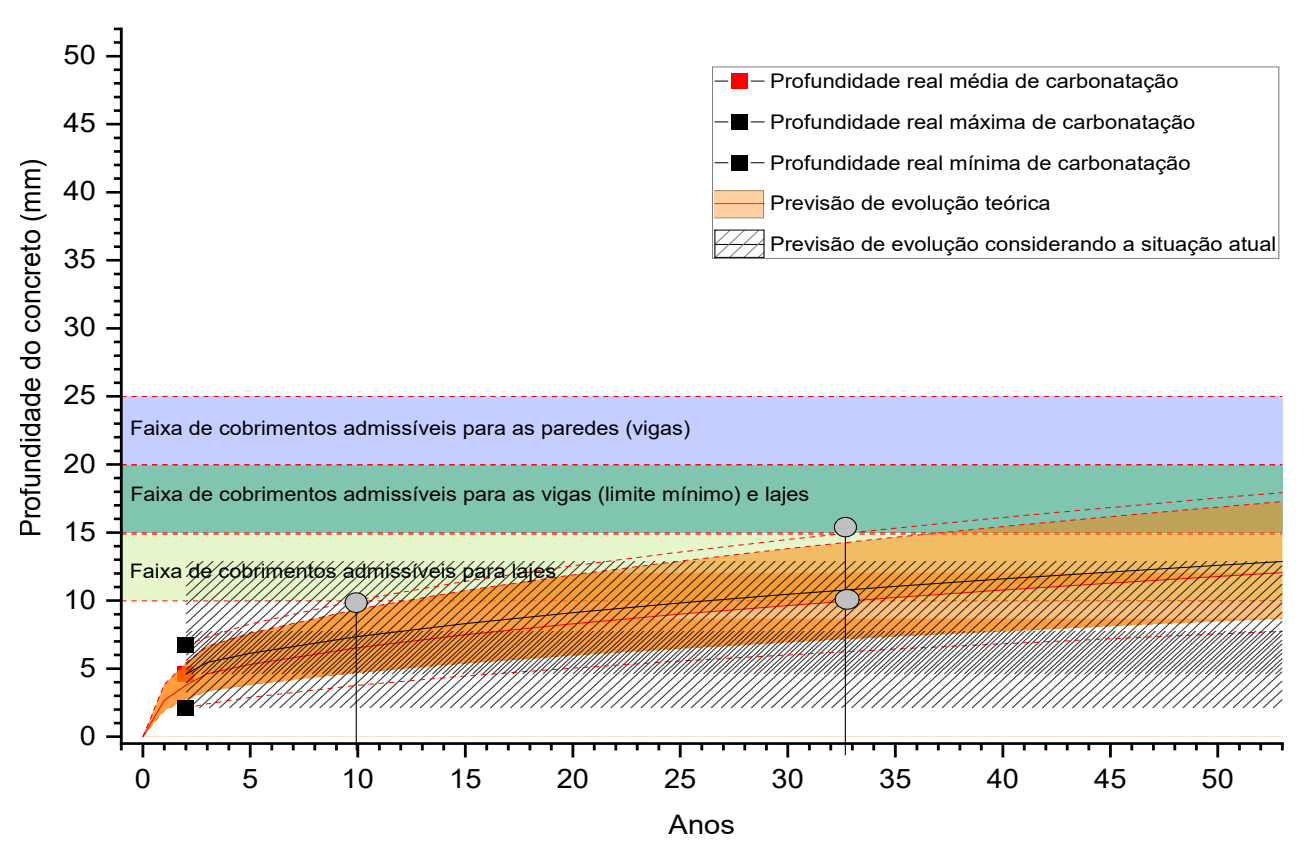

Figura 12. Evolução da frente de carbonatação para concreto do projeto e cobrimentos atendendo a CAA II da NBR 6118.

A frente de carbonatação poderia atingir as armaduras das lajes somente em 10 anos (nas condições atuais, já ocorreu em 2 anos) de forma localizada e pontual. É mais provável que isto iniciasse somente após 30 anos, com pequena probabilidade de que a frente de carbonatação não atingisse as armaduras. Por outro lado, a frente de carbonatação poderia atingir as armaduras das vigas parede somente após 30 anos (nas condições atuais, já ocorreu em 2 anos) de forma localizada e pontual, sendo possível que não houvesse despassivação generalizada durante os 50 anos de vida útil. Portanto, mesmo com a utilização do concreto inadequado, caso os cobrimentos utilizados respeitassem a normativa NBR 6118 (ABNT, 2014), a vida útil da estrutura seria prolongada.

\subsubsection{Projeção na situação real, com concreto mais poroso, menor $f_{c_{k}} e$ menor cobrimento}

Apresenta-se na Figura 13 a evolução da frente de carbonatação ao longo dos anos (hachurado em linhas cinzas), o cobrimento mínimo e máximo identificado nas janelas de inspeção, bem como a faixa usual de cobrimentos. Faz-se a ressalva que na laje de cobertura existem armaduras aparentes, que já estão despassivadas e em processo de corrosão. 


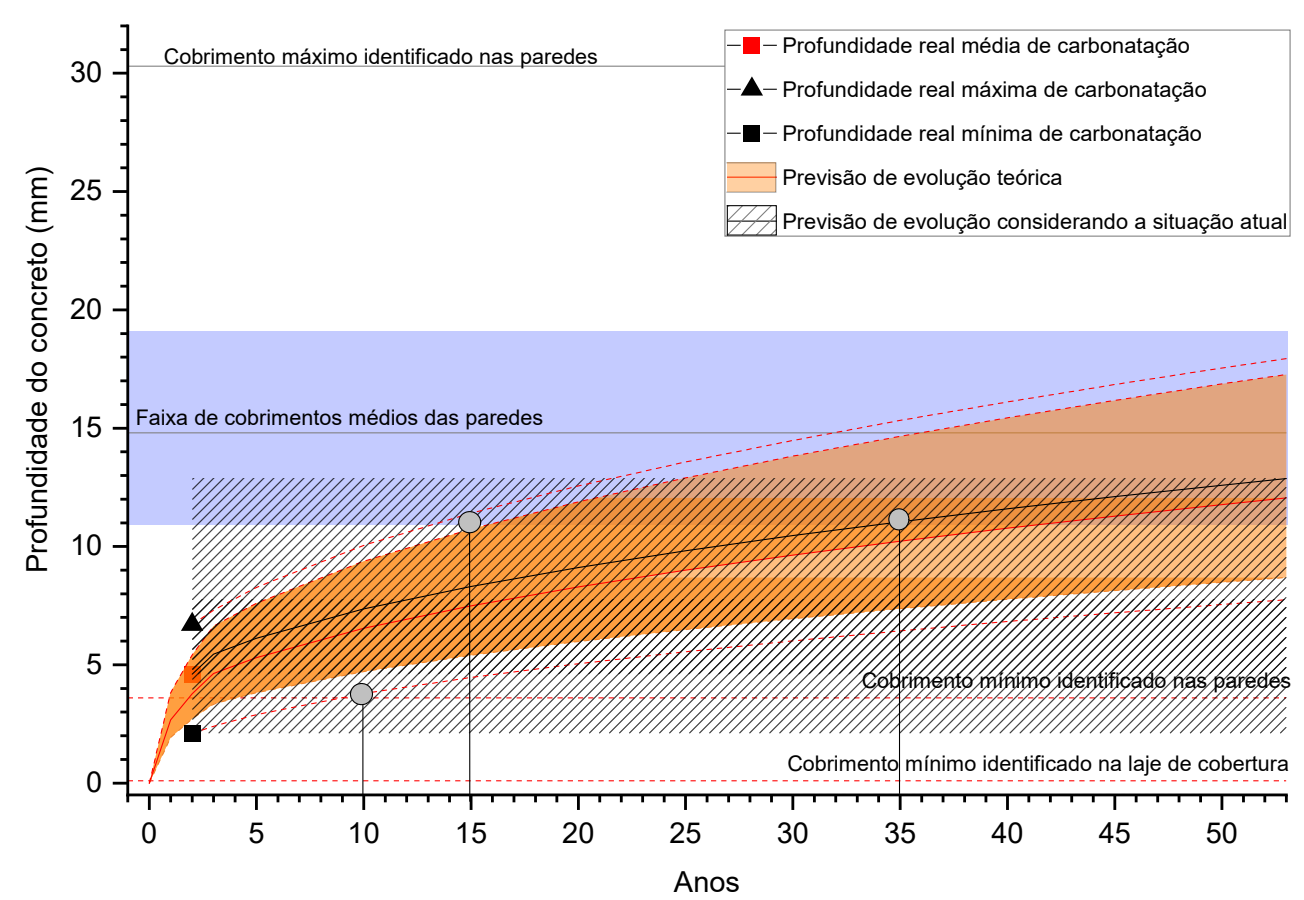

Figura 13. Evolução da frente de carbonatação ao longo dos anos na situação real, com concreto mais poroso, menor $\mathrm{fc}_{\mathrm{k}}$ e menor cobrimento.

A partir do modelo de previsão de vida útil, é possível determinar que:

- Cobrimentos inferiores a $5 \mathrm{~mm}$ já tendem a estar despassivados, indicado pelas manchas de corrosão existentes;

- A partir dos 10 anos da estrutura, os locais despassivados tendem a aumentar progressivamente, pela frente de carbonatação mínima atingir os cobrimentos mínimos;

- Locais com cobrimentos na faixa média de cobrimentos, entre 11 e $18 \mathrm{~mm}$, tendem a iniciar a despassivação a partir dos 15 anos, com probabilidade alta a partir dos 35 anos, quando a frente de carbonatação média atinge esta espessura;

- Há alta probabilidade de que os agentes agressivos atinjam os cobrimentos médios durante os 50 anos de vida útil previstos na NBR 15575-1 (ABNT, 2013);

- A existência de frentes de carbonatação superiores ao máximo determinado pelo modelo de previsão de vida útil na idade atual provavelmente está relacionado à alta relação a/c, superior aos limites da NBR 6118 (ABNT, 2014).

\section{CONCLUSÃO}

Após as análises realizadas, constatou-se que as manifestações patológicas existentes relacionadas à corrosão devem-se à deficiência de cobrimento das armaduras do reservatório, ou seja, à fase de execução. Os pontos de corrosão isolados que se manifestam nas paredes são, em sua maioria, ocasionados por arames que restaram superficiais e despassivaram por carbonatação do concreto de cobrimento. As manchas e aglomerados de produtos de corrosão que surgiram na superfície foram ocasionados pela despassivação por carbonatação das armaduras que tiveram corrosão acelerada, uma vez que o reservatório foi preenchido temporariamente com água e houve aumento de umidade no local. Por outro lado, as eflorescências estão relacionadas à lixiviação de sais solúveis, se manifestando na laje de cobertura onde, na face superior (externa) há acúmulo de água da chuva que penetra no concreto e provoca a lixiviação na face inferior. 
Da análise dos materiais utilizados e informações recebidas, verificou-se que o concreto fornecido possui relação a/c acima do limite especificado na NBR 6118 (ABNT, 2014) para qualquer classe de agressividade ambiental (CAA). Ainda, a normativa indica a necessidade de ser considerado nestes casos os cobrimentos da CAA IV e a NBR 12655 (ABNT, 2015) especifica maior fck e menor relação a/c, sendo que no projeto foi considerada a CAA III para o concreto e CAA II para os cobrimentos.

A existência de pontos de corrosão nesta fase impossibilita o atendimento à vida útil da NBR 15575-1 (ABNT, 2013). A partir dos ensaios eletroquímicos, janelas de inspeção e modelos de previsão de vida útil, determinou-se que há alta probabilidade de que a estrutura tenha novos locais com corrosão, não atingindo a vida útil de 50 anos especificado na Norma. Isto ocorre, pois as características do concreto utilizado e cobrimentos existentes são insuficientes para garantir a durabilidade necessária.

As verificações de durabilidade foram determinadas através de modelos de previsão de vida útil para carbonatação, fenômeno que vêm ocorrendo antes do preenchimento do reservatório e que continuará a ocorrer nas zonas de molhagem e secagem do reservatório (partes superiores e tampa, por exemplo). Não foram utilizados modelos de previsão de vida útil por cloretos, tendo em vista as incertezas dos modelos existentes para estruturas novas, onde ainda não houve penetração deste agente agressivo.

Conforme recomendações da NBR 16747 (ABNT, 2020), as manifestações patológicas e o prognóstico da estrutura indicam a inexistência de durabilidade adequada para a estrutura, trazendo, caso não sejam realizadas adequações, prejuízos à segurança do elemento estrutural. O item é enquadrado como oriundo da fase de projeto e de execução e possui prioridade de reparo elevada, pois provoca a perda de desempenho, compromete a durabilidade e eleva demasiadamente o custo de manutenção.

\section{REFERÊNCIAS}

Andrade, C., Buják, R. (2013), Effects of some mineral additions to Portland cement on reinforcement corrosion. Cement and Concrete Research. (53):59-67. https://doi.org/10.1016/j.cemconres.2013.06.004

Angst, U. M. (2018), Challenges and opportunities in corrosion of steel in concrete. Materials and Structures, 51(1):1-20. https://doi.org/10.1617/s11527-017-1131-6

Angst, U., Moro, F., Geiker, M., Kessler, S., Beushausen, H., Andrade, C., ..., Serdar, M. (2020), Corrosion of steel in carbonated concrete: mechanisms, practical experience, and research priorities-a critical review by RILEM TC 281-CCC. RILEM Technical Letters. (5):85-100. https://doi.org/10.21809/rilemtechlett.2020.127

Associação Brasileira De Normas Técnicas. (2013). NBR 15575: Desempenho de edificações habitacionais. Rio de Janeiro.

Associação Brasileira De Normas Técnicas. (2014). NBR 6118: Projeto de estruturas de concreto - Procedimento. Rio de Janeiro.

Associação Brasileira De Normas Técnicas. (2015). NBR 12655: Concreto de cimento PortlandPreparo, controle, recebimento e aceitação - Procedimento. Rio de Janeiro.

Associação Brasileira De Normas Técnicas. (2020). NBR 16747: Inspeção predial - Diretrizes, conceitos, terminologia e procedimento. Rio de Janeiro.

ASTM International. (2015). ASTM C876-15 Standard Test Method for Corrosion Potentials of Uncoated Reinforcing Steel in Concrete. https://doi.org/10.1520/C0876-15

Chemrouk, M. (2015). The deteriorations of reinforced concrete and the option of high performances reinforced concrete. Procedia Engineering, 125, pp. 713-724. https://doi.org/10.1016/j.proeng.2015.11.112 
Figueira, R. B., Sadovski, A., Melo, A. P., Pereira, E. V. (2017), Chloride threshold value to initiate reinforcement corrosion in simulated concrete pore solutions: The influence of surface finishing and $\mathrm{pH}$. Construction and Building Materials. (141):183-200. https://doi.org/10.1016/j.conbuildmat.2017.03.004

Gentil, V. (2014), "Corrosão". 6. ed. Rio de Janeiro, Livros Técnicos e Científicos, p. 360.

Hansson, C. M. (2016), An introduction to corrosion of engineering materials. In: Poursaee A. "Corrosion of Steel in Concrete Structures". [s. l.], Woodhead Publishing, pp. 3-18.

Junginger, M., Medeiros, J. S. (2002). Ação da eflorescência de carbonato de cálcio sobre o vidrado de placas cerâmicas. Encontro Nacional de Tecnologia do Ambiente Construído. (9).

Lima, M. G. (2011), Ações do meio ambiente sobre as estruturas de concreto. In: Isaia, G. C. "Concreto: Ciência e Tecnologia", São Paulo, IBRACON, v. 1, cap. 21, pp.733-772.

Mehta, P. K., Monteiro, P. J. M. (2014), “Concreto. Microestrutura, propriedades e materiais”. 2 ed. São Paulo, IBRACON, p. 751.

Menezes, R. R., Ferreira, H. S., Neves, G. D. A., Ferreira, H. C. (2006), Sais solúveis e eflorescência em blocos cerâmicos e outros materiais de construção-revisão. Cerâmica, 52(321): 37-49.

Modesti, G. (2020), "Avaliação do efeito da composição da solução dos poros na qualidade da passivação e resistência à corrosão da armadura do concreto”, Dissertação de Mestrado, Universidade do Vale do Rio dos Sinos, p. 130.

Possan, E. (2010), "Modelagem da carbonatação e previsão de vida útil de estruturas de concreto em ambiente urbano", Tese de doutorado, Universidade Federal do Rio Grande do Sul - UFRGS, p. 260. Revert, A. B., De Weerdt, K., Hornbostel, K., Geiker, M. R. (2018), Carbonation-induced corrosion: Investigation of the corrosion onset. Construction and Building Materials. (162):847856. https://doi.org/10.1016/j.conbuildmat.2017.12.066

RILEM, T.C. (2003), "Recommendations of RILEM TC 154-EMC: electrochemical techniques for measuring metallic corrosion half-cell potential measurements-potential mapping on reinforced concrete structures," Materials and Structures, 36(261):61-471.

Stefanoni, M., Angst, U. M., Elsener, B. (2018), Electrochemistry and capillary condensation theory reveal the mechanism of corrosion in dense porous media. Scientific reports, 8(1):1-10. https://doi.org/10.1038/s41598-018-25794-X

Stefanoni, M., Angst, U. M., Elsener, B. (2019), Kinetics of electrochemical dissolution of metals in porous media. Nature materials, 18(9):942-947. https://doi.org/10.1038/s41563-019-0439-8.03.132 Zhu, X., Zi, G., Cao, Z., Cheng, X. (2016), Combined effect of carbonation and chloride ingress in concrete. Construction and Building Materials, (110):369-380. https://doi.org/10.1016/j.conbuildmat.2016.02.034 